\title{
REVIEWS
}

\section{HEREDITY AND EYE DEFECTS}

\section{UNTERSUCHUNGEN ÜBER DIE HEREDITÄT DES STRABISMUS CONCOMITANS (Investigations concerning strabismus concomitants). Dr Susanne Richter. Georg Thieme, Leipzig. 1967. 88 pp. +17 figs.}

The investigation mainly concerns 697 squinting children 4 to 7 years of age who first visited the eye clinic of the Charitè in East Berlin between 1.8.63 and 31.1.65. These unrelated propositi and 3123 of their relatives were thoroughly tested for their ocular functions. In addition among 3398 Berlin pupils, born in 1953, 179 children, about 4 per cent. with strabismus concomitans were found, providing further propositi for the investigation of siblings and parents. In another control group, comprising people of various ages, the condition occurred in 2.7 per cent. of the individuals.

Statistical scrutiny excluded both simple autosomal or recessive inheritance and makes multifactoral determination the most probable. This hypothesis is additionally supported by observations concerning familial and genetically determined sensory and motor defects as well as heterophorias which though they may occur without strabism clearly are components of the condition. A comparison between $\mathrm{MZ}$ and $\mathrm{DZ}$ twins showed concordance of 91.4 per cent. and 25.9 per cent. respectively. Refractory errors affect the strabism to some extent but exogenous factors play only a small part in its causation. Some of the statistics of the paper are rather primitive, but do not invalidate the main conclusions. There is a useful bibliography.

H. Kalmus

Galton Laboratory, University College, London

\section{MENDEL IN TRANSLATION}

THE ORIGIN OF GENETICS: A MENDEL SOURCE BOOK. Edited by C. Stern and E. R. Sherwood. Freeman \& Co. Ltd., San Francisco and London. 1967. Pp. xvi+179. 36s. cloth; 18s. paper.

In May 1900 William Bateson gave the first account in English of Mendel's paper on peas. The occasion was a meeting of the Royal Horticultural Society. One year later the translation of the whole paper which the Society commissioned was published in its journal. From that time until the present it has been reprinted time and time again, for Eva Sherwood's translation is its first competitor. This indicates either that the RHS translation is an excellent one or that geneticists have taken a long time to perceive its faults. A comparison of the two versions shows that the faults are few but not unimportant. It was Dr Alan Robertson in Edinburgh who in 1965 noted some possible inaccuracies and set off the chain of events which led to this new translation. Origins of Genetics consists of a collection of papers and letters on Mendel and his work, some translated for this book, others reprinted from previous publications. I will examine first the translations and second the selection of material. 